\title{
Una revisión de las patentes escolares del Porfiriato. Materiales, hallazgos y posibilidades de análisis
}

\author{
A Review of the Porfirian School Patents: \\ Materials, Findings and Possibilities for Analysis
}

Vandari M. Mendoza ${ }^{1}$

\begin{abstract}
En este trabajo se analizan las patentes de invención escolares que se registraron en el México porfiriano (1876-1911). Para ello, en un primer momento, se aborda el trato que esta fuente ha tenido en la historia de la educación, los documentos que conforman los expedientes de patentes y la clase de datos que poseen estos materiales. En segundo lugar, se exponen los hallazgos que revelan los ritmos de patentamiento, las tendencias de invención y el perfil sociodemográfico de las personas que registraron inventos escolares durante los años del régimen porfirista. Finalmente, se pone sobre la mesa de discusión un conjunto de posibilidades de análisis e interpretación que estas patentes ofrecen para la historia de la educación y para la comprensión del escenario educativo del Porfiriato.
\end{abstract}

Resumen

Palabras clave: Tecnología escolar, Patentes de invención, Porfiriato, Inventores, Objetos

\begin{abstract}
This paper analyzes the patents for school materials which were registered in Porfirian Mexico (18761911). For this aim, the first part examines the treatment that this source has had in the history of education, the documents that contain the patent files, and the kind of data that these materials contain. Beyond, the second part analyzes the findings that reveal the patenting rhythms, invention trends and the sociodemographic profiles of those people who registered inventions for school materials during the years of the Porfirian regime. Finally, this paper opens the discussion about the possibilities for analysis and interpretation that these patents grant for the history of education, as well as for the understanding of the educational scenario of the "Porfiriato".
\end{abstract}

Abstract

Keywords: School Technology, Patents of Invention, Porfiriato, Inventors, Objects

\footnotetext{
${ }^{1}$ Doctor en Historia. Es profesor investigador en la Universidad Pedagógica Nacional, Unidad 161 Morelia. Sus líneas de investigación son la historia de la tecnología, la historia de las patentes de invención en México, la historia de los artefactos escolares y la protección de los conocimientos técnicos tradicionales. Correo electrónico: vanda_manu@ hotmail.com
} 


\section{Introducción}

En la historiografía mexicana cada vez existe una mayor comprensión de los múltiples y diversos perfiles que adoptó la educación durante las décadas que transcurrieron del Porfiriato a la Posrevolución (1876-1940). Cuando menos, en los últimos veinte años, se han diversificado los temas de investigación, se han localizado acervos documentales con información relevante y se han propuesto aproximaciones novedosas para explicar el desarrollo educativo del país. El panorama global de la educación, sin embargo, aún dista mucho de estar completo. Nuevas fuentes documentales, otros agentes históricos y diferentes interpretaciones están en espera de salir a la luz. Al respecto, el asunto de la invención y patentamiento de tecnología escolar es uno de los que prácticamente ha pasado inadvertido en la historiografía nacional, a pesar de su relevancia. Es verdad que se ha estudiado la introducción de algunos materiales, muebles, útiles e instrumentos en los procesos de enseñanza-aprendizaje, pero se ha realizado de forma colateral o sin considerar los artefactos creados en el escenario nacional.

En consecuencia, este descuido ha ocasionado que sean pocos los historiadores que han explotado el fondo de Patentes y Marcas resguardado en el Archivo General de la Nación (ACN). Con excepción de Josefina Granja Castro — quien exhumó y publicó una breve compilación de doce expedientes de patentes educativas (Granja, 2004) - y de algunos esfuerzos aislados que han rescatado un puñado de invenciones producidas por ciertos profesores destacados de la segunda mitad del siglo XIX, o vinculadas con un método pedagógico como la enseñanza objetiva (Mendoza, 2016), este acervo permanece casi inexplorado, en estado prístino para la historia de la educación. Una condición que resulta inquietante si consideramos la cantidad de documentos que posee, la variedad de datos que puede proveer y las posibilidades de interpretación que ofrece para comprender la realidad educativa del país.

Para comenzar a superar este hiato historiográfico, a finales de 2018 se puso en marcha un amplio proyecto de investigación titulado: "La invención de tecnología educativa en una época de transición. Evidencias en el sistema mexicano de patentes, 1890-1942", el cual estriba en recopilar, sistematizar y analizar los datos derivados de dicho acervo documental para presentar las tendencias, continuidades y rupturas que acontecieron en la materia durante los años del México porfiriano y posrevolucionario. ${ }^{2}$ Al respecto, se han venido estudiando las invenciones registradas en las tres décadas y media del Porfiriato, así como los inventos protegidos con la primera legislación de patentes posrevolucionaria (vigente hasta 1942). Esto nos ha dado la posibilidad de reunir, por primera vez, la experiencia mexicana en el ámbito de la

\footnotetext{
${ }^{2}$ Este proyecto de largo aliento se desarrolla en la Universidad Pedagógica Nacional, Unidad 161 Morelia. Comenzó su funcionamiento gracias al soporte institucional del Programa para el Desarrollo Profesional Docente (PRODEP), como parte de la convocatoria de Apoyo a la Incorporación de NPTC-2018.
} 
invención escolar y examinar las múltiples connotaciones que estas creaciones tuvieron en el universo educativo de la época.

Así, en el marco de dicho proyecto de largo aliento, la intención del presente artículo radica en mostrar y examinar los resultados obtenidos a propósito del primer tramo de su delimitación temporal: el Porfiriato. Un ejercicio que consistirá en revisar las patentes escolares de dicho periodo de tres formas distintas y complementarias. En primer lugar, desde una perspectiva heurística - entendida como la búsqueda, recopilación y estudio de la fuente histórica (Matute, 2000)—, se analizará el trato que han tenido las patentes en la historia de la educación, los documentos que conforman sus expedientes y el tipo de datos que poseen. En segundo lugar, como corolario de la revisión heurística, se presentarán los hallazgos históricos que revelan los ritmos de patentamiento, las tendencias de invención y el perfil sociodemográfico de las personas que registraron inventos escolares durante los años del régimen porfirista. Finalmente, a modo de ejercicio hermenéutico, se pondrán sobre la mesa de debate múltiples posibilidades de análisis e interpretación que, desde algunos enfoques teóricos actuales, se desprenden de dichos registros para la historia de la educación y para la comprensión del panorama educativo del Porfiriato.

\section{Los materiales}

Hoy sabemos que las patentes de invención son materiales de primera mano que tienen una gran cantidad de información para reconstruir la experiencia histórica de varios ámbitos de la realidad social (Beatty 2001, 2015; Mendoza, 2018b). Esta documentación, sin embargo, no ha sido aprovechada de manera cabal por todas las ramas del quehacer historiográfico que podrían beneficiarse con su estudio, quizás por desconocimiento de la clase de datos que proporciona, por la predilección de algunos investigadores a trabajar con fuentes conocidas o por ciertas ideas negativas que se han difundido en torno a las patentes. Al respecto, las patentes han sido empleadas esencialmente en la historia de la economía para definir los ritmos y las tendencias del cambio tecnológico y económico en una sociedad. Desde esta especialidad, sin embargo, siempre han sido consideradas con reservas o como una fuente "débil". Esto es así porque se sabe que muchos inventos patentados nunca llegan a construirse ni explotarse comercialmente. Por tanto, se dice que carecen de "trascendencia económica". Algunos autores incluso sostienen que menos del 10\% de las invenciones patentadas llegan a la fase de innovación y comercialización (Layton, 1977: 201), mientras que las restantes permanecen "sin utilidad" o han sido consideradas como una manifestación de la "actividad psicológica de soñadores que reiterada, entusiasta e ingeniosamente ofrecen solución a problemas que principalmente les interesan sólo a ellos" (Basalla, 1991: 93). 
Esta idea negativa ha afectado el valor histórico de esta documentación y, quizás por ello, no ha sido empleada en otros campos historiográficos. En efecto, para la historia económica, la ausencia de explotación de los inventos patentados puede ser un factor que impida medir adecuadamente el cambio tecnológico y económico de una sociedad, pero en otras áreas del quehacer historiográfico los mismos documentos suministran un raudal de datos e información excepcional para comprender fenómenos históricos relevantes como las ideas, los conocimientos, las expectativas y las prácticas tecnológicas de los sujetos de una época, así como las condiciones y dificultades que enfrentaron para desarrollar sus proyectos en contextos específicos. Incluso, la falta de explotación de las patentes no debe juzgarse como rasgo de debilidad, pues desde un ángulo distinto esa condición puede proporcionar indicios muy valiosos para analizar lo que se ha denominado como los "caminos no tomados" (Noble, 1984: 145). Es decir, la tecnología que en algún momento fue proyectada y patentada, pero que nunca se construyó por motivos técnicos, sociales, políticos, económicos o ideológicos.

En la historia de la educación, específicamente, han sido pocos los historiadores que han trabajado estos materiales. Las patentes han sido tratadas con indiferencia o, en el mejor de los casos, como objetos exóticos con "un contenido insólito que provoca, como primera reacción, la tentación de desecharlos por incomprensibles y poco fidedignos" (Granja, 2004: 27). Una reacción que resulta hasta cierto punto extraña si consideramos que las patentes ofrecen información constante — de naturaleza cualitativa y cuantitativa - para conocer y examinar múltiples aspectos del fenómeno educativo. En este sentido, cabe mencionar que cada patente de invención genera un expediente con una cantidad significativa de papeles que poseen información de diferente índole y alcance para la historia de la educación. En líneas generales, la documentación producida es la siguiente: solicitud, descripción, reivindicaciones, dibujos, documentos administrativos y título de concesión. En teoría, todos estos papeles son públicos

y uniformes, aunque se pueden encontrar restricciones y variaciones en función del momento histórico o la legislación de cada país.

La solicitud es el documento donde el inventor (o su apoderado) pide formalmente el registro del objeto en cuestión ante la autoridad competente y lleva a cabo una primera exposición general de su propuesta inventiva. En este escrito, además, por lo regular aparecen datos muy relevantes de carácter social. Ahí, por ejemplo, se indica el género, nacionalidad, residencia, profesión, apoderados, testigos y empresas vinculadas al inventor. De la misma manera, en los registros del siglo XIX — cuando las solicitudes no habían sido estandarizadas o no estaban ceñidas a las camisas de fuerza del formulario-, los inventores aprovechaban este espacio para expresar un sinfín de cavilaciones, comentarios y observaciones personales. Por ejemplo, los esfuerzos físicos, materiales e intelectuales que habían realizado para desarrollar sus creaciones; las ventajas que sus inventos significaban para mejorar las condiciones del entorno local, nacional e internacional; los antecedentes técnicos que habían superado con sus propuestas; e 
incluso la situación política, económica y social del contexto en el que estaban inmersos. En fin, la riqueza y diversidad de estas declaraciones depende de la personalidad de cada personaje (Mendoza, 2018a).

Por otra parte, la descripción, los dibujos y las reivindicaciones son los documentos medulares de las patentes desde un punto de vista técnico. Ahí se encuentran las ideas y saberes que son objeto de patentamiento. Por ley, la descripción debe señalar de forma clara todos los elementos y relaciones que constituyen la invención. Es decir, se trata de un espacio para codificar y formalizar los nuevos conocimientos e ideas técnicos de manera que sean lo suficientemente explícitos para que un experto pueda replicarlos. Los dibujos, entre tanto, no sólo tienen la finalidad de ejemplificar la constitución física del invento, también representan una tentativa de capturar los saberes tácitos que no se pueden expresar de manera escrita. Las reivindicaciones, en cambio, son unos cuantos párrafos donde el inventor expresa de manera concisa lo que debe proteger la patente. En otras palabras, es donde declara con total exactitud la esencia de la invención (Mendoza, 2018a).

Por último, los documentos administrativos también proporcionan muchos datos de interés para el historiador. Cada expediente puede contener, dependiendo del caso y la naturaleza de la invención, el dictamen de la Oficina de Patentes sobre la suficiencia o insuficiencia de los documentos presentados; las cartas de oposición interpuestas por personajes o empresas que sentían lesionados sus derechos; los exámenes de novedad solicitados con anterioridad por el inventor para confirmar la primicia de su propuesta; las sentencias de comisiones expertas que definían la viabilidad o salubridad de ciertas invenciones; los recibos de las cuotas anuales de renovación o extensión del periodo de protección; las cartas poder delegando la representación legal en conocidos, abogados o agentes especializados en la materia; y las asignaciones a terceros de los derechos de patente. (Mendoza, 2018a).

Toda esta documentación, sin duda, ofrece información valiosa para la historia de la educación. Los expedientes de patentes suministran datos sobre los ritmos y tendencias de creación tecnológica en distintos niveles formativos; son una ventana que permite visualizar con claridad los intereses, motivaciones y expectativas de los sujetos que incursionaron en la creación de técnicas, artefactos, útiles, mobiliario e infraestructura educativa; son una fuente privilegiada para identificar el perfil socioeconómico de los actores sociales que registraron invenciones escolares y para descubrir su relación con el mundo académico; son un venero de información sistemática sobre la nacionalidad, la residencia, el género, la profesión, el nivel de estudios, los intermediarios y las redes de cooperación de los inventores. En suma, son una fuente que, más allá de su discutido provecho económico, ofrecen testimonios diversos y valiosos sobre asuntos cruciales del ambiente socioeducativo.

Más aún, las patentes proporcionan datos sobre la realidad material de las escuelas, los objetos dirigidos a brindar apoyo a la enseñanza y las prácticas efectuadas al interior del salón 
de clases para mejorar los procesos de aprendizaje. Por ello, como se detallará más adelante, podemos aproximarnos al estudio de esta fuente desde la perspectiva de la cultura material de la escuela; un enfoque que ha cobrado importancia en los últimos años, al grado que algunos autores hablan de la existencia de un "giro material" en la historiografía de la educación (Dussel, 2019). Asimismo, podemos complementar este acercamiento con un análisis constructivista, entendiendo que los inventos patentados fueron resultado de complejos entramados específicos, donde las condiciones sociales, materiales y técnicas desempeñaron un papel crucial (Cutcliffe, 2003).

\section{Los hallazgos}

En este apartado presentaremos los resultados del trabajo de investigación documental no sólo para mostrar las tendencias generales de patentamiento en materia escolar, sino también un conjunto de datos sociodemográficos - derivados de los expedientes de patentes-, que nos permitirán delinear el perfil de los actores sociales que incursionaron en la arena de la creación y registro de invenciones escolares durante el Porfiriato. Al respecto, los datos obtenidos durante la fase heurística de la investigación, descrita en el apartado anterior, se sistematizaron con el fin de resolver cuatro asuntos nodales para comprender el fenómeno de la invención escolar del Porfiriato: ¿Cuántos inventos se registraron?, ¿qué variaciones se presentaron durante el periodo analizado?, ¿qué clase de objetos se registraron? y ¿quiénes fueron los sujetos que patentaron objetos escolares? La respuesta a estas preguntas nos dará un primer panorama de los distintos hechos o hilos de realidad que urdieron la trama de la creación y registro de inventos escolares; panorama que posteriormente será problematizado con la propuesta de diversas posibilidades de análisis que nos ofrecen estos datos.

En primer lugar, antes de presentar el volumen anual y los ritmos de patentamiento, es conveniente mencionar que las patentes escolares fueron un acontecimiento porfiriano, pues prácticamente todos los registros se produjeron durante este periodo, salvo la primera patente que fue expedida pocos meses antes de su comienzo, el 30 de marzo de 1876, por un "sistema de enseñanza en las escuelas", cuyo autor fue el profesor de primeras letras Clemente Antonio Neve. ${ }^{3}$ Después de esta primera invención, ya durante el régimen porfirista, se presentó un reducido registro de patentes, hasta que el volumen comenzó a incrementarse hacia la década de 1890, alcanzando su mayor concentración en la última década del Porfiriato. Incluso, como se puede apreciar en la tabla l, existieron años con una proporción muy significativa de patentes como lo fueron 1904, 1905, 1909 y 1910.

${ }^{3}$ AGN, Patentes y Marcas, Caja 12, Exp. 774, Clemente Antonio Neve, Sistema de enseñanza en las escuelas, 30 de marzo de 1876 
Tabla 1

Volumen anual de patentes escolares, 1876-1911

\begin{tabular}{|c|c|}
\hline Año & Patentes \\
\hline 1876 & 0 \\
\hline 1877 & 0 \\
\hline 1878 & 1 \\
\hline 1879 & 0 \\
\hline 1880 & 0 \\
\hline 1881 & 1 \\
\hline 1882 & 1 \\
\hline 1883 & 0 \\
\hline 1884 & 1 \\
\hline 1885 & 1 \\
\hline 1886 & 0 \\
\hline 1887 & 1 \\
\hline
\end{tabular}

\begin{tabular}{|c|c|}
\hline Año & Patentes \\
\hline 1888 & 1 \\
\hline 1889 & 1 \\
\hline 1890 & 1 \\
\hline 1891 & 0 \\
\hline 1892 & 1 \\
\hline 1893 & 0 \\
\hline 1894 & 1 \\
\hline 1895 & 2 \\
\hline 1896 & 1 \\
\hline 1897 & 1 \\
\hline 1898 & 1 \\
\hline 1899 & 2 \\
\hline
\end{tabular}

\begin{tabular}{|c|c|}
\hline Año & Patentes \\
\hline 1900 & 2 \\
\hline 1901 & 3 \\
\hline 1902 & 2 \\
\hline 1903 & 8 \\
\hline 1904 & 12 \\
\hline 1905 & 12 \\
\hline 1906 & 7 \\
\hline 1907 & 6 \\
\hline 1908 & 6 \\
\hline 1909 & 12 \\
\hline 1910 & 11 \\
\hline 1911 & 3 \\
\hline
\end{tabular}

Fuente: elaboración propia con base en los expedientes del fondo de Patentes y Marcas del AGN y los registros de la Gaceta Oficial de la Oficina de Patentes y Marcas.

De este modo, de acuerdo con nuestras pesquisas, ahora sabemos que durante los años del régimen porfirista en total se patentaron ciento dos invenciones escolares por personajes que radicaban en México. Asimismo, podemos identificar que, a partir de la década de 1890, aumentó de manera significativa la cantidad de patentes obtenidas, manifestándose también un mayor dinamismo en la materia. De hecho, resulta evidente que las dinámicas de patentamiento se distribuyeron en tres segmentos temporales con ritmos bastante disímiles: el primero de 1876 a 1889, el segundo de 1890 a 1902 y el tercero de 1903 a 1911. Durante el primer periodo, los inventores únicamente lograron obtener ocho patentes, lo que significa un invento cada dos años; en el segundo, se observa un incremento sustancial con diecisiete patentes, lo que corresponde a poco más de un invento anual; mientas que durante el tercero se dio un fuerte crecimiento, con un total de setenta y siete patentes, esto es, más de ocho inventos por año, en promedio. 
Tabla 2

Ritmos de patentamiento anual, 1876-1911

\begin{tabular}{|c|c|c|c|}
\hline Periodo & Años & Patentes & Promedio anual \\
\hline $1876-1889$ & 14 & 8 & 0.6 \\
\hline $1890-1902$ & 13 & 17 & 1.3 \\
\hline $1903-1911$ & 9 & 77 & 8.5 \\
\hline
\end{tabular}

Fuente: elaboración propia con base en los expedientes del fondo de Patentes y Marcas del AGN y los registros de la Gaceta Oficial de la Oficina de Patentes y Marcas.

Cabe señalar que estas variaciones en el volumen y el ritmo de las invenciones registradas, coinciden con los años de promulgación de las leyes de patentes del Porfiriato (1890 y 1903), cada una de las cuales significó una importante modernización en la materia que condujo a un incremento global de inventos patentados (Beatty 1996, 2001). Al iniciar el Porfiriato, la ley que regulaba al sistema mexicano de patentes era antigua y discrecional, había sido promulgada desde 1832 y estaba en la órbita jurídica de los antiguos privilegios exclusivos que premiaban con monopolios a quienes introducían tecnología del exterior o comenzaban actividades económicas inéditas en el país, lo que propiciaba procesos de innovación más que de invención (Mendoza, 2012). En este sentido, Beatty y Sáiz (2007) señalan que "la concesión y administración de dichos privilegios rara vez propició códigos legales unificados, lo que significa que se asignaron discrecionalmente, que su alcance fue muy diverso y que sus especificaciones fueron muy vagas" (p. 428). Por ello, ante la falta de garantías, no es extraño que existan pocos inventos patentados durante los catorce años que esta ley estuvo vigente en la época porfiriana. Además, se debe considerar que la cuota para obtener una patente era bastante onerosa, llegando incluso al nivel del ingreso anual de un artesano urbano (Mendoza, 2018b: 132).

Más tarde, en 1890, fue promulgada la primera legislación de patentes porfiriana que, basándose en los patrones establecidos en Estados Unidos, Inglaterra y Francia, definió claramente los procedimientos y criterios para la concesión de las patentes, limitando la protección a los verdaderos inventos y dejando de lado la introducción de tecnología o de actividades industriales (Beatty, 1996). En su contenido se indicaba explícitamente que las patentes sólo podían concederse por invenciones que "tuvieran como objeto un nuevo producto industrial, un nuevo método de producción o una nueva aplicación de métodos conocidos para obtener un resultado o producto industrial" (Torre, 1903: 18-19). Esto, sin duda, fue un aliciente para los auténticos inventores de objetos escolares que repercutió en el 
volumen anual de patentes, el cual incrementó poco más del doble en promedio. Sin embargo, esta ley conservó costos de registro demasiado elevados y fue poco divulgada entre los segmentos sociales que podían beneficiarse con su amparo (Mendoza, 2018b). De ahí que la cantidad de patentes haya continuado siendo limitada.

Finalmente, en 1903, se promulgó una detallada y rigurosa legislación que estableció las bases del moderno sistema de patentes mexicano. Fue un dispositivo legal muy bien diseñado en sus fundamentos, procedimientos administrativos y sanciones judiciales, instaurando condiciones mucho más apropiadas para el registro, protección y divulgación de las verdaderas invenciones. Por ejemplo, protegió exclusivamente las creaciones intelectuales de carácter técnico, estableció una gran reducción en las tarifas de patentamiento, instauró mecanismos eficientes de difusión y circuló en amplios sectores de la sociedad porfiriana. Estas modificaciones legales, sin duda, repercutieron de manera positiva en el registro de patentes, propiciando su crecimiento exponencial.

No obstante, como se ha analizado ampliamente en otros estudios, junto con la paulatina modernización institucional, se produjeron otras transformaciones profundas en el contexto sociotécnico porfiriano que permitieron el incremento sustancial de patentes en el periodo de 1903 a 1911 (Mendoza, 2018b). Sería demasiado extenso citarlas aquí, solo cabe subrayar que, entre las más relevantes, estuvo el desarrollo del sistema educativo.

En segundo lugar, en cuanto a las temáticas de invención, el acervo de patentes nos muestra que las tendencias principales se manifestaron en tres esferas: objetos didácticos, útiles escolares y mobiliario escolar. Como se puede apreciar en la tabla 3 (y con mayor detalle en el anexo final), las materias de los inventos patentados se encuentran en estrecha relación con las ideas pedagógicas que se estaban discutiendo en la escena nacional y que aparecieron, por ejemplo, en los cuatro congresos pedagógicos del Porfiriato (1882, 1889, 1890-1891 y 1910). Aspectos como el mobiliario, los útiles, los materiales didácticos e incluso la configuración de los espacios para una adecuada enseñanza a los estudiantes, aparecen también como temas del imaginario y de las preocupaciones de los inventores mexicanos. De este modo, las patentes evidencian un interés de distintos actores sociales por idear, proponer y crear artefactos y procedimientos que resolvieran las necesidades educativas que se expresaban en el ambiente de la época. 
Tabla 3

Temáticas de invención, 1876-1911

\begin{tabular}{|c|c|c|}
\hline Temática & Patentes & Porcentaje \\
\hline Objetos didácticos & 45 & $44 \%$ \\
\hline Útiles escolares & 35 & $35 \%$ \\
\hline Mobiliario escolar & 22 & $21 \%$ \\
\hline
\end{tabular}

Fuente: elaboración propia con base en los expedientes del fondo de Patentes y Marcas del AGN y los registros de la Gaceta Oficial de la Oficina de Patentes y Marcas.

Así, en la esfera de los inventos didácticos, se pueden encontrar desde complejos sistemas pedagógicos para la enseñanza primaria, hasta artefactos muy simples para el aprendizaje del uso de patines, pasando por silabarios mecánicos, instrumentos para la enseñanza de la lectoescritura, métodos y aparatos para que los alumnos aprendieran "fácil" y "velozmente" geografía, aritmética, taquigrafía, anatomía, dibujo, teneduría de libros, música, escritura en máquina e incluso para dominar el arte de tejer y bordar con telares de mano. Del mismo modo, existe una cantidad nada despreciable de juegos didácticos para el aprendizaje objetivo, el conocimiento de los sucesos históricos y los héroes nacionales, así como un procedimiento para dar ocupación a los estudiantes de primaria durante el tiempo que no recibían lecciones orales, utilizando para ello unas hojas que su inventor denominó "Trabajos en Silencio". ${ }^{4}$ Este amplio repertorio de inventos, sin duda, nos muestra un ambiente creativo en términos didácticos.

En la esfera de los útiles escolares, mientras tanto, quedaron registradas invenciones que buscaban resolver las necesidades más básicas y cotidianas del mundo educativo. Así, por ejemplo, los inventores mexicanos idearon pinzas, reglas, lápices, gises, crayones, lapiceros, papeles especiales, estuches, tinteros, libros con hojas copiadoras, carpetas, tajadores o sacapuntas, portaplumas y una asombrosa variedad de artefactos para realizar operaciones matemáticas: desde los simples ábacos para niños pequeños, hasta sofisticados aparatos mecánicos para realizar cálculos aritméticos con nombres bastante extravagantes como "Abanico Multiplicado Automático", "Aritmeotáxica Ríos", "Redina Mexicana" o "Aritmómetro Tabla Neperiana". Incluso, más allá de los útiles, en el ámbito de los uniformes escolares, se patentaron unos zapatos que su inventor, Miguel González Muñoz, denominó "blindados", teniendo en consideración el uso rudo que los niños ejercen sobre el calzado. ${ }^{5}$ En todas estas creaciones siempre

${ }^{4} \mathrm{ACN}$, Patentes y Marcas, Lista dispuesta por orden de clases y subclases de las patentes que se expidieron conforme a la ley de 7 de junio de 1890 hasta el 30 de septiembre de 1903, Abel José Ayala, Hojas para dar ocupación a los alumnos "Trabajos en Silencio", 21 de mayo de 1901.

${ }^{5}$ AGN, Patentes y Marcas, Lista dispuesta por orden de clases y subclases de las patentes que se expidieron conforme a la ley de 7 de junio de 1890 hasta el 30 de septiembre de 1903, Miguel González Muñoz. Sistema de calzado blindado "Calzado escolar", 19 de julio de 1898. 
se hallan pequeños (o grandes) cambios y adecuaciones en objetos conocidos para hacer más útiles los útiles, imprimirles otros sentidos, crear nuevas experiencias e incluso para servir como instrumentos didácticos.

Por último, en la esfera del mobiliario escolar existe un conjunto no muy numeroso, pero significativo, de objetos que pretendían mejorar las experiencias formativas de los alumnos en el salón de clases. Tras múltiples discusiones que se dieron, por ejemplo, en el Congreso Higiénico Pedagógico de 1888, donde participaron profesores y médicos, se adquirió conciencia sobre la necesidad de crear muebles y espacios adecuados para la salud, el desarrollo y la anatomía de los alumnos. Para cubrir estas necesidades, los inventores mexicanos patentaron pizarrones, atriles, bancas, mesabancos, escritorios, bastidores para costura, mesas de dibujo y aparatos gimnásticos que buscaban mejorar la salud y capacidad física de los niños. Incluso, más allá de lo que podemos considerar propiamente como mobiliario, aparece el modelo de un edificio escolar que respondía a los planteamientos médicos y pedagógicos de la época. ${ }^{6}$ En este sentido, se recomendaba que las escuelas tuvieran condiciones higiénicas (luminosidad, ventilación y amplitud), así como evitar "los caños abiertos, mingitorios en el zaguán y depósitos de basura" (Bazant, 1995: 22).

En tercer lugar, con relación a las características sociodemográficas de los personajes que patentaron creaciones escolares durante el Porfiriato, se pueden localizar datos en verdad interesantes sobre el género, la nacionalidad, la residencia y la profesión que permiten dibujar un cuadro más o menos detallado del papel que estos sujetos desempeñaban en la sociedad, los espacios de trabajo donde se desenvolvían, las condiciones económicas que poseían e incluso algunos rasgos culturales como la vinculación de las actividades tecnológicas con ciertos roles y estereotipos de género.

Por lo que atañe al género, precisamente, lo primero que salta a la vista es la casi exclusiva presencia de hombres. Sólo se encuentra el caso de una mujer, la profesora de primaria superior, María Muñoz Silva, quien patentó un "bastidor para dar clases de costura simultánea para niñas"? Esta clase de relegación de las mujeres en la arena de la invención patentada resulta esclarecedora para comprender el ambiente de producción tecnológica que se vivía en aquel entonces. En este sentido, si bien es cierto que la presencia de las mujeres en el campo magisterial fue considerable durante el Porfiriato, pues la docencia a nivel básico se consolidó como una profesión feminizada (Loyo y Staples, 2010: 135), no fue suficiente para que pudieran incursionar en el terreno de la invención tecnológica, el cual ya se había erigido socioculturalmente como un espacio masculino.

${ }^{6}$ AGN, Patentes y Marcas, Leg. 191, Exp. 119, Román Navarro y Cortés, Modelo de un inmueble escolar, 2 de agosto de 1910.

${ }^{7}$ AGN, Patentes y Marcas, Leg. 169, Exp. 1, María Muñoz Silva, Bastidor para dar clases de costura simultánea para niñas, 7 de mayo de 1904. 
Como lo mencionan Ruth Oldenziel (1999) y Judy Wajcman (2006), durante el siglo XIX se consolidó el estereotipo cultural que, todavía en el presente, consagra a la tecnología como actividad predominantemente masculina: los músculos, la fuerza, la destreza para solucionar problemas, la habilidad mecánica, la racionalidad técnica y el taller como espacio de trabajo se convirtieron en coto de los hombres y en recursos de poder (Wajcman, 2006: 172). Todo esto, sin duda, hizo muy complicado que las mujeres pudieran incursionar en la arena de la invención, pues su marginación del trabajo técnico impidió que adquirieran la experiencia y los saberes tácitos indispensables para la creación tecnológica (Mendoza, 2018b: 498).

En cuanto a la nacionalidad, el segmento mayoritario que patentó objetos escolares fue de inventores mexicanos, sólo dieciocho personajes pertenecían a otros países, especialmente España, como se puede apreciar en la tabla 4. La colonia española fue la que tuvo mayor presencia global en las patentes mexicanas, junto con la estadounidense, aunque esta última no ejerció un papel significativo en la invención de objetos escolares. La amplia participación de ambos países en las patentes mexicanas es comprensible si consideramos que nutrieron los principales flujos de migración al país durante el Porfiriato (González, 1993). Asimismo, el descuelle de los inmigrantes españoles en la invención escolar se debe a que establecieron un vínculo más estrecho con el mundo educativo que los norteamericanos. En todos los niveles formativos no era extraño encontrar, por lo menos, un reconocido profesor hispánico. Por ende, no debe extrañar su presencia en el terreno de las patentes educativas. Del mismo modo, es preciso señalar que todos los inventores extranjeros estudiados en este artículo residían en México. Como se ha demostrado en otros estudios, los sujetos radicados en países donde no nacieron suelen comportarse de manera semejante a los nacionales, pues ambos (nativos y extranjeros) están sujetos a las mismas condiciones del contexto local (Sáiz, 2002).

Tabla 4

Nacionalidad de los inventores, 1876-1911

\begin{tabular}{|c|c|}
\hline País & Patentes \\
\hline México & 84 \\
\hline España & 10 \\
\hline
\end{tabular} \begin{tabular}{|c|c|}
\hline País & Patentes \\
\hline EUA & 3 \\
\hline Francia & 3 \\
\hline
\end{tabular} \begin{tabular}{|c|c|c|}
\hline Pais & Patentes \\
\hline Alemania & 1 \\
\hline Italia & 1 \\
\hline
\end{tabular}

Fuente: elaboración propia con base en los expedientes del fondo de Patentes y Marcas del AGN y los registros de la Gaceta Oficial de la Oficina de Patentes y Marcas.

A propósito de la residencia, también es interesante observar que la gran mayoría de los inventores del Porfiriato radicaba en la Ciudad de México. La preeminencia de la capital del país en la esfera de las patentes de invención ya ha sido explicada en otros trabajos (Gardiner, 1949; 
Mendoza 2018b). Entre los motivos que originaron este predominio se ha mencionado que la atmósfera industrial y mercantil de la capital ofrecía mejores posibilidades financieras que estimulaban a los inventores; que su ambiente cosmopolita, progresista y científico inspiraba a muchos a inventar; que había mejores condiciones materiales y recursos técnicos para desarrollar los inventos; que la región del Valle de México era el territorio más densamente poblado de toda la nación; y que los residentes de la capital eran más propensos a ser conscientes de la propia existencia del sistema de patentes, siendo bastante probable que muchos habitantes de provincia ni siquiera conocieran las funciones de la institución. Sólo cabría añadir que, en el ámbito educativo, la Ciudad de México concentraba los principales espacios escolares del país, poseía los índices más altos de alfabetismo y ahí se llevaron a cabo los congresos educativos del Porfiriato que repercutieron en las tendencias inventivas, como lo mencionamos con anterioridad.

Tabla 5

Residencia de los inventores, 1876-1911

\begin{tabular}{|c|c|}
\hline Entidad & Patentes \\
\hline Ciudad de México & 76 \\
\hline Nuevo León & 8 \\
\hline Veracruz & 3 \\
\hline Estado de México & 2 \\
\hline Michoacán & 2 \\
\hline Querétaro & 2 \\
\hline Tamaulipas & 2 \\
\hline Coahuila & 1 \\
\hline Durango & 1 \\
\hline Jalisco & 1 \\
\hline Morelos & 1 \\
\hline Puebla & 1 \\
\hline Yucatán & 1 \\
\hline Zacatecas & 1 \\
\hline
\end{tabular}

Fuente: elaboración propia con base en los expedientes del fondo de Patentes y Marcas del ACN y los registros de la Gaceta Oficial de la Oficina de Patentes y Marcas.

Finalmente, el dato de profesión es el que arroja una mayor dispersión estadística, aunque con los profesores a la cabeza por obvias razones. No obstante, si realizamos un ejercicio de agru- 
pamiento por volumen de patentes, claramente aparecen tres bloques. Así, una tercera parte de los inventos escolares fue producida por profesores (32 patentes); otra tercera parte fue generada por cuatro profesiones: comerciantes, ingenieros, abogados e industriales (35 patentes); mientras que la última tercera parte está distribuida entre veinte profesiones distintas (33 patentes). Es evidente, entonces, que numéricamente los profesores, ingenieros, comerciantes, abogados e industriales fueron los actores colectivos más relevantes en el campo de la invención escolar patentada, encabezados claramente por los sujetos que estaban más estrechamente vinculados al mundo escolar.

Tabla 6

Profesiones declaradas por los inventores, 1876-1911

\begin{tabular}{|c|c|}
\hline Profesión & Patentes \\
\hline Profesor & 32 \\
\hline Comerciante & 11 \\
\hline Ingeniero & 11 \\
\hline Abogado & 7 \\
\hline Industrial & 6 \\
\hline Sin dato & 6 \\
\hline Tenedor de libros & 4 \\
\hline Editor & 3 \\
\hline Empleado & 3 \\
\hline Empresario & 3 \\
\hline Fotógrafo & 3 \\
\hline Agricultor & 2 \\
\hline Electricista & 2 \\
\hline
\end{tabular}

\begin{tabular}{|c|c|}
\hline Profesión & Patentes \\
\hline Artesano & 1 \\
\hline Carpintero & 1 \\
\hline Dibujante & 1 \\
\hline Grabador de metal & 1 \\
\hline Horticultor & 1 \\
\hline Impresor & 1 \\
\hline Empresa & 1 \\
\hline Mecánico & 1 \\
\hline Mecanografista & 1 \\
\hline Médico & 1 \\
\hline Músico & 1 \\
\hline Sastre & 1 \\
\hline Zapatero & 1 \\
\hline
\end{tabular}

Fuente: elaboración propia con base en los expedientes del fondo de Patentes y Marcas del AGN y los registros de la Gaceta Oficial de la Oficina de Patentes y Marcas.

Los profesores tuvieron una participación muy importante en la invención de objetos didácticos, pues prácticamente la mitad de las patentes de esa esfera fue producida por ellos (22 de 45 patentes), mientras que el resto se desperdigó en trece profesiones distintas. Sin duda, la presencia de los profesores en la invención de objetos didácticos era predecible, lo que sorprende positivamente es hallar agricultores, electricistas, fotógrafos y mecánicos, pues esto sugiere que el ambiente de renovación pedagógica de la época se extendió a otros sectores 
sociales que pusieron sus ideas y conocimientos al servicio del mejoramiento de los procesos de enseñanza-aprendizaje de los alumnos.

Los comerciantes, mientras tanto, fueron quienes sobresalieron en la esfera de los útiles escolares con siete patentes, seguidos por los ingenieros con seis y los profesores con cinco. En este sentido, es interesante observar que este ámbito de la invención estuvo "dominada" por dos profesiones no magisteriales - aunque a veces los practicantes de otras actividades también desempeñaban labores docentes complementarias-, seguramente porque se trata del campo donde menos experiencia frente a grupo se requería. En cambio, era necesario otro tipo de conocimiento para crear objetos como máquinas para realizar cuentas, fórmulas para fabricar gises, papeles especiales, lápices para recordar anotaciones y calendarios de diversa utilidad, todo lo cual formó parte de la inventiva de estos profesionistas.

Por otra parte, los profesores e industriales fueron quienes tuvieron mayor presencia en la esfera del mobiliario escolar con cinco patentes cada grupo. Esa presencia puede considerarse natural, pues los profesores eran quienes conocían por experiencia directa las características que debían tener los espacios, el mobiliario y los utensilios que serían ocupados o usados por los estudiantes (y por ellos mismos), mientras que los industriales eran las personas que poseían los saberes, herramientas y maquinarias más adecuados para construir objetos como mesabancos, pizarras, escritorios y atriles en sus talleres especializados.

Finalmente, no podemos dejar de mencionar que los abogados, el otro grupo relevante de profesionistas, distribuyó su actividad inventiva de manera más o menos homogénea en las principales esferas de invención escolar de la época: tres patentes de mobiliario, dos de útiles escolares y dos de objetos didácticos; lo cual refleja cierta versatilidad de los practicantes de dicha profesión en la arena inventiva.

\section{Las posibilidades de análisis}

Las 102 patentes escolares del Porfiriato contienen una gran cantidad de datos sobre los objetos, los sujetos y las prácticas educativas. Sin embargo, más allá de la información de primera mano que nos pueden entregar, estas evidencias del pasado también nos permiten pensar, desde el presente, en diversas posibilidades de interpretación histórica. Al respecto, enseguida formularemos algunas alternativas hermenéuticas que se derivan de esta fuente para la historia de la educación en general y para la comprensión del fenómeno educativo del Porfiriato en particular, a la luz de ciertas tendencias teóricas actuales y problemas que han permanecido como asignaturas pendientes en esta rama del quehacer historiográfico.

De entrada, consideramos conveniente inscribir el estudio de las patentes escolares en la tendencia historiográfica de trabajos sobre la cultura material de la escuela, una corriente en la 
historia de la educación que recientemente se ha desarrollado con ímpetu, buscando ofrecer explicaciones a sucesos que eran difíciles de historiar o formular nuevas interpretaciones de los que ya habían sido abordados. En efecto, como lo mencionamos con anterioridad, en la última década los historiadores del mundo educativo han configurado una aproximación cada vez más compleja y profunda sobre la materialidad de lo escolar, nutriendo sus indagaciones con ideas, reflexiones y teorías de disciplinas diversas como la sociología, la antropología, la arqueología e incluso la museología. Así, han logrado analizar las diversas connotaciones de lo material (patios, salones, ventanas, paredes, libros de texto, cuadernos, útiles escolares, pupitres, mesabancos, artefactos didácticos, uniformes, etc.) en los procesos educativos y coadyuvar a la preservación de ese patrimonio cultural.

Desde esta amalgama de saberes interdisciplinarios, entonces, se sostiene que los objetos no son realidades subyacentes de la acción humana, sino entidades que desempeñan roles de importancia equiparable al que desempeñan las personas en los procesos sociales. Por tanto, deben estudiarse bajo el "principio de la simetría" propuesto originalmente por David Bloor (1976), ampliado por Michel Callon (1986) e impulsado a su nivel más radical por Bruno Latour (2005). Este principio indica que las entidades humanas, naturales y artefactuales son "actantes" en redes o entramados heterogéneos, donde el investigador no debe presuponer la preponderancia de alguna sobre otra. Por ejemplo, no es adecuado considerar las relaciones entre humanos como más relevantes que las que se producen entre humanos y no humanos. Como lo expresa Inés Dussel (2019), el enfoque de la cultura material de la escuela:

[...] supone incluir a los objetos y las cosas como partícipes plenos en la red de lo social, como actores o "actantes" - como los Ilama Latour (2005) — que no son sólo ni principalmente la proyección de nuestras acciones sino que también nos hacen realizar acciones o sentir emociones. Hay una simetría en esa interacción humanosobjetos que hay que considerar como punto de partida de la investigación; en esa dirección, habría que ir más allá de decir que la historia de un artefacto depende de los usos y sentidos que le damos a los objetos y buscar atender a lo que ese artefacto produjo en la nueva red humanos-objetos que se creó a partir de su presencia. En otras palabras, el giro material no busca animar lo inanimado (no es que de pronto los objetos "cobren vida"), sino darles a los objetos un espesor y una capacidad de acción no intencionada pero incluyente en el curso de la historia humana. Somos lo que somos por la interacción con los objetos, así como ellos lo son por esas interacciones (pp. 17-18)

Desde luego, las patentes de invención, por su propia naturaleza jurídica, no proveen los objetos físicos para examinarlos - aunque en ocasiones los expedientes contienen modelos a escala o prototipos de los inventos-, sino una documentación sui generis que describe detalladamente su configuración técnica y funcionamiento, así como una serie de datos de 
carácter social, económico, cultural y político del contexto en el que se formaron. Esto hace de las patentes una fuente excepcional para la historia de la cultura material de la escuela, pues ni los propios objetos físicos podrían otorgar esta clase de información. Además, cabe mencionar que, contrario a lo que sucede con el resto de las patentes, en el caso de las escolares un número significativo fue puesto en práctica. Esto lo sabemos porque más del $40 \%$ de los inventos registrados durante el Porfiriato fueron resultado de la experiencia, la práctica profesional de docentes o el ensayo con alumnos, tal como se desprende de las propias declaraciones que se hallan en los expedientes.

Así, con base en estos planteamientos teóricos, muchas patentes pueden coadyuvar al análisis y comprensión de las prácticas educativas. Sobre este punto debemos señalar que en la historia de la educación se ha mantenido latente un problema crucial: la falta de elementos para reconstruir la vida al interior del salón de clases. Desde hace algunas décadas, por ejemplo, Harold Silver (1992) advertía que los estudios históricos habían olvidado a los alumnos, su comportamiento en el interior de las aulas, los objetos didácticos instrumentados y las prácticas asociadas a ellos. Estos auténticos "silencios" en la historia de la educación, han originado que muchos investigadores permanezcan en el vestíbulo de las escuelas, sin posibilidad de cruzar la reja de entrada, debido al tenaz desconocimiento de la vida académica dentro de las instituciones y los salones de clases.

Esta situación, difícil de vencer por la naturaleza y alcance de muchas fuentes usuales, se puede resolver parcial y satisfactoriamente con el estudio de las patentes escolares. En efecto, los documentos de un buen número de patentes nos pueden ayudar al entendimiento de las prácticas educativas dentro del salón de clases, especialmente aquellas que giran en torno a objetos didácticos, mobiliario o útiles escolares que fueron desarrollados por profesores o que tenemos certeza de su instrumentación. En estos casos, sabemos que las invenciones interactuaron con los sujetos, propiciando un cúmulo de experiencias y dinámicas educativas que simplemente no se hubieran generado - o habrían acontecido de manera diferente- en su ausencia. Este tipo de patentes, entonces, posee información valiosa sobre objetos que detonaron vivencias y participaron de forma plena y simétrica (con estudiantes y profesores), en espesos entramados de significados y acciones. Nos brindan, por tanto, extraordinarias posibilidades de análisis e interpretación para descubrir las interacciones entre diversos "actantes" en los procesos educativos. Además, como lo veremos después, estos hallazgos pueden complementarse con las intenciones declaradas por los propios inventores en sus solicitudes y descripciones.

Más aún, las patentes también pueden ayudarnos a resolver y analizar otra dificultad que ha causado mucha incertidumbre en la historia de la educación y que denominamos como el problema de la "traducción operativa". En otros términos, siempre ha resultado complicado evidenciar las conexiones existentes entre las ideas de un modelo educativo -las cuales se 
presentan como saberes autorizados en los tratados, planes, programas, leyes, estatutos o políticas institucionales - y la instrumentación de tales premisas que permanecen como saberes soterrados, porque están ocultos en las prácticas cotidianas de los sujetos y los objetos (Foucault, 2003: 16). Por fortuna, las patentes pueden coadyuvar al entendimiento de este fenómeno, pues nos muestran un conjunto de iniciativas donde es posible observar la manera como circularon y se comprendieron los principios pedagógicos de la época — por ejemplo, la enseñanza objetiva o el positivismo-, así como las acciones y creaciones realizadas por algunos sujetos para materializar las premisas de lo que "debería ser" la educación desde cierto modelo o enfoque teórico.

Asimismo, sabemos que ninguna traducción puede ser completamente fidedigna, pues en el trayecto de una condición a otra se presentan distorsiones, hibridaciones y adecuaciones. Es muy interesante, entonces, analizar las intersecciones y los diálogos que se producen entre los múltiples saberes que configuran a las propuestas inventivas. En este sentido, las patentes poseen un enorme abanico de saberes heterogéneos: pedagógicos, mecánicos, explícitos y tácitos; en ocasiones contienen saberes profesionales y muchas veces informales. Como lo expresa Granja (2004), las patentes escolares "ponen de manifiesto fusiones, mezclas y transposiciones entre el saber pedagógico de la época y los saberes populares que subyacen en el diseño, uso y beneficio de los inventos presentados" (p. 39). Esto, sin duda, constituye un enorme campo de reflexión e interpretación histórica.

Relacionado con lo anterior, las patentes escolares también hacen visible a "sujetos de la educación" que habían pasado totalmente inadvertidos o que no eran plenamente reconocidos como tales. Más allá de los actores tradicionales — profesores, estudiantes, padres de familia, autoridades, etcétera-, las patentes muestran en acción a sujetos de diversa ocupación que de alguna manera estaban comprometidos con el desarrollo de las prácticas o experiencias educativas. Por ejemplo, en el caso de las patentes de la era porfiriana, si bien es verdad que casi una tercera parte fueron obtenidas por profesores, la mayoría pertenecen a personas con ocupaciones diversas: comerciantes, ingenieros, abogados, industriales, tenedores de libros, agricultores, fotógrafos, empleados, electricistas y una plétora de oficios que, por algunos motivos, sobre los cuales es necesario indagar y reflexionar, se mostraron interesados en transformar ciertas prácticas o experiencias escolares con sus propuestas inventivas.

Desde otro ángulo, para complementar lo anterior, las patentes escolares también permiten analizar los inventos producidos por sujetos "plenamente" reconocidos como educativos, pero proveyendo información original y valiosa que con dificultad se puede hallar en otras fuentes. Por ejemplo, proporcionan datos sobre lo que se ha identificado como la configuración de saberes educativos en las "zonas capilares de producción", al nivel de los operadores inmediatos de la enseñanza: los profesores y sus experiencias cotidianas. Más aún, por el bajo perfil que predomina entre los maestros que patentaron durante el Porfiriato, podemos 
adentrarnos en el horizonte de las prácticas periféricas, aquellas que no quedaron registradas en los discursos de los grandes educadores, los tratados pedagógicos o las leyes del ramo, sino que fueron efectuadas desde los márgenes por estos actores subalternos en espacios educativos reales.

Del mismo modo, las patentes escolares no sólo nos proporcionan información sobre las prácticas y experiencias concretas que pudieron detonar los inventos registrados, también son un venero de datos para analizar los significados que esos objetos tuvieron para sus creadores. Aquí entramos de lleno al terreno de las voliciones, las expectativas o los deseos de aquellos que crearon y patentaron objetos escolares. Ya sabemos que con estos documentos se pueden examinar los saberes, perfiles sociodemográficos, tendencias y ritmos de patentamiento, pero también poseen testimonios para estudiar las intenciones de los inventores: sus intereses, anhelos y pretensiones. Así, vienen a llenar la ausencia de voz que muchas veces padecen los creadores de objetos educativos en las investigaciones históricas. En efecto, a diferencia de otras fuentes directas que usualmente se emplean para reconstruir la historia material de la escuela - como las fotografías, los videos, los uniformes o los propios objetos físicos que se exponen en museos-, las patentes de invención proveen datos sobre las voliciones de los creadores de tecnología escolar de viva voz de sus autores, lo cual abre un amplio abanico de posibilidades para analizar los significados que ellos mismos le otorgaron a sus creaciones y las transmutaciones que experimentaron con su empleo en las aulas.

Por otra parte, las patentes educativas poseen información importante para rastrear, examinar y comprender las formas de producción y circulación de los saberes en diferentes entidades. En las solicitudes y descripciones muchas veces aparecen indicios relevantes de los itinerarios gnoseológicos que transitaron los inventores para construir sus propuestas: las experiencias constructivas; los consejos y asesorías que obtuvieron de especialistas, tanto en aspectos técnicos como pedagógicos; los ensayos que practicaron en espacios educativos; las apropiaciones de ideas de inventos precedentes; y las cavilaciones en las que se sumergieron los propios inventores. En suma, podemos identificar los saberes que se pusieron en marcha, y los que se fueron adhiriendo, durante el trayecto de configuración de los objetos escolares patentados. Una dinámica que ya ha sido estudiada en otros campos de invención, como es el caso de las máquinas desfibradoras de henequén (Mendoza, 2017).

Asimismo, por medio de las patentes podemos analizar los fenómenos de desplazamiento y circulación de los saberes que fueron incorporados a las invenciones escolares en distintos territorios y escalas espaciales. A nivel local, por ejemplo, la existencia de redes, grupos o relaciones de colaboración, proporciona información sobre los conocimientos técnicos y/o pedagógicos que se transmitieron en dichos entramados. A nivel global, mientras tanto, los datos de nacionalidad y residencia son cruciales para explorar estos desplazamientos. Por un lado, el dato de nacionalidad nos permite conocer el nivel de saberes foráneos y nacionales que circu- 
laban en el sistema de patentes, los países de procedencia y las conexiones existentes entre inventores de distinto origen. Por otro lado, un análisis cruzado entre nacionalidad y residencia nos ofrece la posibilidad de ubicar a los personajes que, en calidad de inmigrantes, patentaron objetos educativos en el país. Así, acudiendo a fuentes complementarias, podemos rastrear los conocimientos que poseían (y que viajaron con ellos), dándonos elementos para dilucidar los complejos acontecimientos de encuentro, adaptación, resistencia, apropiación o hibridación que indefectiblemente se produjeron al ser desplazados y adoptados en sitios externos al de su creación (Mendoza, 2018a).

Por último, los hallazgos obtenidos conducen a la identificación de las patentes como un acervo relevante para el estudio y preservación del patrimonio material de la escuela de los siglos XIX y XX. Más allá de que quizás algunas patentes nunca se introdujeron en la práctica educativa, o que tal vez tuvieron alcance limitado, hoy constituyen un valioso referente del modo en que se vivió, proyectó y repensó la escuela en un momento dado. Así, mediante su estudio y exposición, se pueden divulgar los distintos significados que tuvieron los materiales didácticos, útiles, muebles, edificios y demás objetos patentados durante el Porfiriato.

\section{Consideraciones finales}

En este recorrido por las patentes escolares del Porfiriato hemos podido constatar que esta fuente documental aporta diversas posibilidades heurísticas y hermenéuticas para la historia de la educación y para la comprensión de las dinámicas educativas de la era porfiriana. En este sentido, además de los datos concretos que nos ofrece para conocer las fibras internas del fenómeno inventivo - cantidad de patentes, ritmos de registro, temáticas de invención, distribución territorial de las creaciones, así como un conjunto de datos sociodemográficos y biográficos de los sujetos que patentaron-, también nos otorga elementos para reflexionar, analizar e interpretar múltiples aspectos de la historia de la educación que han sido soslayados o para los que no se tenían evidencias suficientes.

De esta manera, el estudio de las patentes escolares nos proporciona nuevos datos y promueve otras miradas para ampliar nuestra comprensión del complejo mundo de las concepciones, los sujetos, los objetos y las prácticas educativas. De hecho, como lo referimos a lo largo de este trabajo, a través de las patentes se pueden estudiar cada una de estas entidades o, mejor dicho, se pueden desenmarañar para analizar sus especificidades y conexiones, porque en los hechos se encuentran fusionadas.

Así, en cuanto a las concepciones, las patentes no sólo nos muestran las expectativas, los deseos y las ideas educativas de los inventores, sino sus propuestas de "traducción operativa" para adecuar las políticas, modelos y teorías pedagógicas a las necesidades particulares de los 
espacios educativos, con los complejos eventos de adaptación e hibridación que conllevan dichos procesos. Respecto a los sujetos, nos permiten trazar un perfil relativamente detallado del mundo material de los inventores (posición social, profesión, relaciones interpersonales, etc.) y de su realidad inmaterial (saberes, voliciones, imaginarios, etc.). Acerca de los objetos, nos ofrecen la posibilidad de identificar su configuración y funcionamiento técnico, así como los conocimientos explícitos y tácitos que están embebidos en ellos. Por último, en cuanto a las prácticas educativas, nos colocan en posición de examinar las múltiples maneras en que los inventos patentados se introdujeron en entramados heterogéneos, donde ideas, sujetos y objetos interactuaron de manera simétrica, produciendo experiencias y significados diversos.

En virtud de lo anterior, consideramos que estas complejas intersecciones se pueden entender mejor (o con mayor profundidad) si se abordan desde una postura teórica clara. En este sentido, el estudio de las patentes escolares desde los principios teóricos adoptados por la historia de la cultura material de la escuela, nos permite examinar con profundidad las múltiples expresiones del fenómeno inventivo, reflexionar sobre sus causas y consecuencias, identificar sus interconexiones y reconstruir -mediante un ejercicio hermenéutico de interpretación histórica-, el tipo de prácticas que estos inventos produjeron en espacios educativos concretos. Esto con el fin de aproximarnos a la comprensión de los saberes y experiencias que realmente acontecieron en las aulas. Conocimientos y vivencias que estaban anclados en las condiciones del contexto donde se desarrollaron, a necesidades particulares, con posibilidades y restricciones especiales. Por tanto, también consideramos que un enfoque constructivista es indispensable para aquilatar las múltiples aristas de las patentes escolares, en función de las condiciones específicas del escenario donde aparecieron.

Asimismo, desde estos enfoques teóricos, el estudio de las patentes educativas del pasado nos permite apreciar algunas continuidades que han permanecido soterradas en la historia educativa del país. En particular, nos muestra el papel esencial (y poco reconocido) que han desempeñado los profesores como creadores de objetos escolares y didácticos. Un papel que ha permanecido eclipsado por el imperio de los tratados pedagógicos, las políticas educativas, los planes y programas de estudios. Tanto más, un papel que todavía en el presente permanece sumergido - por ejemplo, bajo la lógica instrumentalista del modelo por competencias, que coloca al profesor como un simple facilitador de experiencias-, pero que en realidad se halla presente en múltiples espacios y experiencias educativas.

Por tanto, un atributo esencial de las patentes escolares del Porfiriato radica en que - por primera vez en la historia de México, de manera continua y sistemática- dejaron constancia de estas expresiones creativas de los profesores, las cuales siempre han inundado los salones de clases, posibilitando formas heterogéneas de aprendizaje. Expresiones situadas, adaptadas a las condiciones y necesidades locales, que posicionan a muchos profesores como hacedores de saberes pedagógicos, incluso más relevantes que aquellos que circularon por los caminos 
formales. Ahora, corresponde a los historiadores re-presentar estas expresiones para alcanzar una mayor comprensión de las dinámicas educativas, sus múltiples "actantes", y corregir las versiones distorsionadas o incompletas del fenómeno educativo donde los docentes aparecen como simples facilitadores o, en el peor de los casos, con roles pasivos.

En el contexto porfiriano, entonces, los 102 inventos patentados reflejan una imagen nueva y desconocida de la vida escolar; un panorama mucho más activo y creativo de lo que regularmente se piensa con respecto a la creación e innovación tecnológica. Las poco más de cien patentes escolares poseen una significativa cantidad de ideas, experiencias y saberes que anticipan la existencia de un ambiente social dinámico, de transformación educativa y de constante búsqueda de alternativas para cambiar y mejorar los procesos de enseñanzaaprendizaje. Sin duda, esta imagen sólo constituye una pequeña muestra de las acciones que llevaron a cabo distintos actores sociales para renovar las prácticas educativas, así como un panorama inicial que debe complementarse con una reducción de escala para observar los entramados particulares donde se produjeron las patentes escolares del Porfiriato. Por tanto, en posteriores estudios, será necesario dilucidar esas especificidades, atendiendo algunos de los hallazgos y posibilidades hermenéuticas que presentamos en este artículo.

\section{Anexo}

Relación de patentes escolares mexicanas, 1876-1911

\begin{tabular}{|c|l|l|c|}
\hline AÑo & \multicolumn{1}{|c|}{ INVENTOR(ES) } & \multicolumn{1}{|c|}{ INVENTO PATENTADO } & TIPO \\
\hline 1878 & Aurelio Andrade & Sistema de pizarras calcantes & Didáctico \\
\hline 1881 & Valeriano Lara & $\begin{array}{l}\text { Aparato diseñado para enseñar a leer, denomi- } \\
\text { nado "Silabario Mecánico" }\end{array}$ & Didáctico \\
\hline 1882 & $\begin{array}{l}\text { Clemente Antonio } \\
\text { Neve }\end{array}$ & Máquina intuitiva para la enseñanza escolar & Didáctico \\
\hline 1884 & Juan de Dios Nosti & $\begin{array}{l}\text { "Gekinógrafo" que sirve para explicar los fenó- } \\
\text { menos cosmográficos }\end{array}$ & Didáctico \\
\hline 1885 & Manuel Gallegos & Sistema de atriles articulados para estudio & Mobiliario \\
\hline 1887 & Pomposo Becerril & $\begin{array}{l}\text { Método práctico recreativo para aprender } \\
\text { simultáneamente geografía y aritmética }\end{array}$ & Didáctico \\
\hline 1888 & Mariano Botello & $\begin{array}{l}\text { Aparato mecánico que nombra "Atril automá- } \\
\text { tico" }\end{array}$ & Mobiliario \\
\hline 1889 & José P. Arriaga & $\begin{array}{l}\text { Composición para fabricar piezas artificiales } \\
\text { del cuerpo humano, destinadas a estudios } \\
\text { anatómicos. }\end{array}$ & Didáctico \\
\hline
\end{tabular}




\begin{tabular}{|c|c|c|c|}
\hline 1890 & Manuel Oviedo Alzúa & $\begin{array}{l}\text { Abanico "Multiplicador automático" por medio } \\
\text { del cual se pueden ejecutar las multiplicaciones } \\
\text { de los números enteros. }\end{array}$ & Didáctico \\
\hline 1892 & $\begin{array}{l}\text { Cruz Ríos y Juan de } \\
\text { Dios Ávalos }\end{array}$ & $\begin{array}{l}\text { Aparato mecánico "Aritmeotáxica Ríos" para } \\
\text { sumar o multiplicar violentamente todas las } \\
\text { cantidades que puedan formarse con los diez } \\
\text { primeros guarismos de la numeración. }\end{array}$ & Útiles \\
\hline 1894 & Miguel Arriaga Lasaga & $\begin{array}{l}\text { Mapamundi-meridiano-horario universal. } \\
\text { Aparato por el que resuelve, de una manera } \\
\text { práctica, problemas de geografía. }\end{array}$ & Didáctico \\
\hline 1895 & José P. Arriaga & $\begin{array}{l}\text { Preparación aplicable a la fabricación de miem- } \\
\text { bros artificiales del cuerpo humano, e imitación } \\
\text { de los mismos para colecciones de museos } \\
\text { anatómicos y que podrán servir para el estudio } \\
\text { de la cirugía. }\end{array}$ & Didáctico \\
\hline 1895 & Jesús A. Ayala & Pizarrón múltiplo-económico & Mobiliario \\
\hline 1896 & Miguel Arriaga Lasaga & $\begin{array}{l}\text { Sistema de mapas casquetes esféricos y } \\
\text { altimétricos }\end{array}$ & Didáctico \\
\hline 1897 & $\begin{array}{l}\text { Cía. del Lápiz del } \\
\text { Águila }\end{array}$ & Mejoras en lápices & Útiles \\
\hline 1898 & $\begin{array}{l}\text { Miguel González } \\
\text { Muñoz }\end{array}$ & Sistema de calzado blindado "Calzado escolar" & Útiles \\
\hline 1899 & Miguel Oscoy & $\begin{array}{l}\text { Aparato para la enseñanza del dibujo en } \\
\text { perspectiva }\end{array}$ & Didáctico \\
\hline 1899 & Eufemio Cervantes & $\begin{array}{l}\text { Banca para escuela "Banca Escolar Potosina } \\
\text { Eugenio Cervantes" }\end{array}$ & Mobiliario \\
\hline 1900 & Manuel G. Amador & $\begin{array}{l}\text { Juego titulado "Geografía recreativa de la } \\
\text { República Mexicana" }\end{array}$ & Didáctico \\
\hline 1900 & $\begin{array}{l}\text { Ignacio Hernández } \\
\text { Zamudio }\end{array}$ & $\begin{array}{l}\text { Aparato para hacer verdaderamente objetiva la } \\
\text { enseñanza de la teneduría de libros "Legismó- } \\
\text { grafo" }\end{array}$ & Didáctico \\
\hline 1901 & Abel José Ayala & $\begin{array}{l}\text { Procedimiento para dar ocupación a los alum- } \\
\text { nos en las escuelas primarias durante el tiempo } \\
\text { que no reciben lecciones orales, utilizando para } \\
\text { ello unas hojas que denomina "Trabajos en } \\
\text { Silencio" }\end{array}$ & Didáctico \\
\hline 1901 & Mariano de la Garza & $\begin{array}{l}\text { Método moderno simplificado de taquigrafía } \\
\text { universal y rayado especial para la aplicación de } \\
\text { dicho método }\end{array}$ & Didáctico \\
\hline 1901 & Alberto Robles Gil & Calendario perpetuo & Útiles \\
\hline 1902 & $\begin{array}{l}\text { Braulio Zertuche, } \\
\text { Encarnación Dávila y } \\
\text { Juan Cabello y Siller }\end{array}$ & $\begin{array}{l}\text { Procedimiento para hacer gises, tizares o } \\
\text { creyones, así como bloques en diversas formas, } \\
\text { para que los niños adquieran de paso nociones } \\
\text { de arquitectura }\end{array}$ & Útiles \\
\hline
\end{tabular}




\begin{tabular}{|c|c|c|c|}
\hline 1902 & Adolfo Martínez Urista & $\begin{array}{l}\text { Papel especial con transportadores y cuadrícula } \\
\text { fijos }\end{array}$ & Útiles \\
\hline 1903 & Manuel Beltrán & $\begin{array}{l}\text { "Regla decimal Beltrán" para enseñar a los } \\
\text { niños la lectura y escritura de las cantidades } \\
\text { numéricas }\end{array}$ & Didáctico \\
\hline 1903 & Manuel Beltrán & $\begin{array}{l}\text { "Mapas Beltrán" de la República Mexicana y de } \\
\text { sus Estados, Distrito Federal y Territorios }\end{array}$ & Didáctico \\
\hline 1903 & $\begin{array}{l}\text { Gallegos Hermanos, } \\
\text { Sucesores }\end{array}$ & $\begin{array}{l}\text { Mesa-banco binaria y unitaria de madera para } \\
\text { escuelas }\end{array}$ & Mobiliario \\
\hline 1903 & $\begin{array}{l}\text { Francisco Suárez } \\
\text { Peredo }\end{array}$ & $\begin{array}{l}\text { Máquina para hacer cuentas "Contómetro } \\
\text { Mexicano" }\end{array}$ & Útiles \\
\hline 1903 & Pedro Rivero Noriega & $\begin{array}{l}\text { Procedimiento para jugar lotería "Lotería } \\
\text { Objetiva" }\end{array}$ & Didáctico \\
\hline 1903 & Nicasio Luis Barbieri & $\begin{array}{l}\text { Tintero que puede servir por varios años sin } \\
\text { necesidad de ponerle tinta "Tintero Universal" }\end{array}$ & Útiles \\
\hline 1903 & Juan B. Chávez & Aparato gimnástico "Chávez" & Mobiliario \\
\hline 1903 & B. Juan Soldevila & $\begin{array}{l}\text { Sistema para encontrar cualquier población o } \\
\text { lugar marcado en un mapa, cualquier punto } \\
\text { en un mapa o cualquier calle en un plano de } \\
\text { ciudad }\end{array}$ & Didáctico \\
\hline 1904 & Ernesto Fernández & $\begin{array}{l}\text { Teclado de combinación para facilitar el estudio } \\
\text { y la práctica de escritura en máquina }\end{array}$ & Didáctico \\
\hline 1904 & George W. Cook & $\begin{array}{l}\text { Perfeccionamientos en una mesa escritorio } \\
\text { escolar }\end{array}$ & Mobiliario \\
\hline 1904 & María Muñoz Silva & $\begin{array}{l}\text { Bastidor para dar clases de costura simultánea } \\
\text { para niñas }\end{array}$ & Mobiliario \\
\hline 1904 & Guillermo Artigas & $\begin{array}{l}\text { Máquina para aprender a ejercitar el dedo o } \\
\text { manipulación de los teclados de las máquinas } \\
\text { de escribir "Dedeo" }\end{array}$ & Didáctico \\
\hline 1904 & Gonzalo de la Torre & Modelo de "Standard Rapid Calculator" & Útiles \\
\hline 1904 & Herminio Chacón & Aparato para multiplicar números enteros & Útiles \\
\hline 1904 & $\begin{array}{l}\text { Luis Romero y Bernar- } \\
\text { do Romero }\end{array}$ & $\begin{array}{l}\text { Aparato para voltear automáticamente hojas } \\
\text { de libros }\end{array}$ & Mobiliario \\
\hline 1904 & Francisco M. Ortiz & Libro con hojas copiadoras & Útiles \\
\hline 1904 & Inocencio Malabehar & Juego objetivo & Didáctico \\
\hline 1904 & Luis C. Sandoval & Modelo de un estuche carpeta para dibujo & Útiles \\
\hline 1904 & Baldomero de la Prida & $\begin{array}{l}\text { Mejoras en aparatos o telares de mano para } \\
\text { tejer y bordar, denominado "Telar escolar" }\end{array}$ & Didáctico \\
\hline 1904 & Antonio Pons & $\begin{array}{l}\text { Ábaco que simplifica y facilita el aprendizaje de } \\
\text { la aritmética }\end{array}$ & Didáctico \\
\hline 1905 & $\begin{array}{l}\text { Federico Phillippe } \\
\text { Serrano }\end{array}$ & Mesa de dibujo con corredoras móviles & Mobiliario \\
\hline 1905 & Andrés Oscoy & Juego para niños "Ciclo Heroico" & Didáctico \\
\hline
\end{tabular}




\begin{tabular}{|c|c|c|c|}
\hline 1905 & Francisco Romero & $\begin{array}{l}\text { Sistema para hallar un punto cualquiera en todo } \\
\text { un mapa o plano }\end{array}$ & Didáctico \\
\hline 1905 & Francisco Gómez Pérez & $\begin{array}{l}\text { Anillos para aprender a escribir mecánicamente } \\
\text { en máquina }\end{array}$ & Didáctico \\
\hline 1905 & Ernesto Fernández & $\begin{array}{l}\text { Teclado escolar para facilitar el estudio de } \\
\text { escribir a máquina }\end{array}$ & Didáctico \\
\hline 1905 & Miguel Vallejo & $\begin{array}{l}\text { Aparto para operaciones elementales de } \\
\text { aritmética }\end{array}$ & Útiles \\
\hline 1905 & Miguel Vallejo & Ábaco individual para niños & Didáctico \\
\hline 1905 & Miguel Vallejo & Ábaco individual para niños con alfabeticón & Didáctico \\
\hline 1905 & Cosme Cuéllar & Aparato porta-pastas para rayar & Útiles \\
\hline 1905 & A. Merceret & Atril o porta-papel o porta-libro & Mobiliario \\
\hline 1905 & $\begin{array}{l}\text { Julio Hertzog De- } \\
\text { launey }\end{array}$ & Modelo de un calendario & Útiles \\
\hline 1905 & Felipe Sierra & Pie de banca escolar & Mobiliario \\
\hline 1906 & Longinos Cadena & $\begin{array}{l}\text { Teclado cromático para pianos, sistema musical } \\
\text { "Cadena" teclado de piano }\end{array}$ & Didáctico \\
\hline 1906 & Rafael Mallén & Tajador de lápices & Útiles \\
\hline 1906 & Francisco Guasco & Un aparato "Kairográfo eléctrico Guasco" & Didáctico \\
\hline 1906 & Luis G. Unda & Contador automático de seguridad & Útiles \\
\hline 1906 & José Joaquín Terrazas & Máquina para sumar, restar, dividir y multiplicar & Útiles \\
\hline 1906 & $\begin{array}{l}\text { Francisco Suárez } \\
\text { Peredo }\end{array}$ & Aparato para sumar "Taquímetro Mexicano" & Útiles \\
\hline 1906 & Samuel Chávez & Modelo de un mueble para dibujo & Mobiliario \\
\hline 1907 & José G. García & $\begin{array}{l}\text { Dibujo de un geneagrama vertical redondo para } \\
\text { escritura }\end{array}$ & Didáctico \\
\hline 1907 & José G. García & $\begin{array}{l}\text { Dibujo de un geneagrama oval derecho para } \\
\text { escritura }\end{array}$ & Didáctico \\
\hline 1907 & José G. García & $\begin{array}{l}\text { Dibujo de un generagrama oval inclinado para } \\
\text { escritura }\end{array}$ & Didáctico \\
\hline 1907 & José G. García & $\begin{array}{l}\text { Caja enciclopédica para enseñar el primer año } \\
\text { escolar }\end{array}$ & Didáctico \\
\hline 1907 & Fernando Loyola & Pulsera desligadora para el estudio del piano & Didáctico \\
\hline 1907 & Pioquinto J. A. López & Atril automático & Mobiliario \\
\hline 1908 & V. Moisés Torreblanca & Porta-pluma "Guadalupe" & Útiles \\
\hline 1908 & Alberto Isaak & $\begin{array}{l}\text { Aparato portador flexible de lápiz o pluma } \\
\text { "Siempre Pronto" }\end{array}$ & Útiles \\
\hline 1908 & Fernando Loyola & Mejora en la pulsera desligadora & Didáctico \\
\hline 1908 & P. Arteaga y S. & Mejoras en Atriles & Mobiliario \\
\hline
\end{tabular}




\begin{tabular}{|c|c|c|c|}
\hline 1908 & Arturo Rodríguez & $\begin{array}{l}\text { Banca de madera para escuela imitando las de } \\
\text { fierro con movimiento giratorio en el asiento }\end{array}$ & Mobiliario \\
\hline 1908 & José Joaquín Terrazas & Calculador gráfico instantáneo & Útiles \\
\hline 1909 & Luis C. Silicio & Pelotón para jugar y hacer ejercicios musculares & Mobiliario \\
\hline 1909 & Félix García Narro & Atril para mecanografía & Mobiliario \\
\hline 1909 & José Coudurier & Aparato para sumar, restar, multiplicar o dividir & Útiles \\
\hline 1909 & Rogiero Lang & $\begin{array}{l}\text { Aparato de estudio para la enseñanza de } \\
\text { escritura o dibujo }\end{array}$ & Didáctico \\
\hline 1909 & José Joaquín Terrazas & $\begin{array}{l}\text { Lápiz calculador y recordador de anotaciones } \\
\text { varias }\end{array}$ & Útiles \\
\hline 1909 & Pío Sánchez & Lapicero calendario & Útiles \\
\hline 1909 & Felipe Pérez Uribe & $\begin{array}{l}\text { Aritmómetro para expeditar los cálculos de } \\
\text { multiplicación y división "Tabla Neperiana" }\end{array}$ & Didáctico \\
\hline 1909 & Inocencio Malabehar & $\begin{array}{l}\text { Aparato verificador de rifas "Rifa objetiva por } \\
\text { vía aérea" }\end{array}$ & Didáctico \\
\hline 1909 & Alfredo Martínez & $\begin{array}{l}\text { Cuadrícula para el cálculo de superficies en } \\
\text { planos }\end{array}$ & Útiles \\
\hline 1909 & $\begin{array}{l}\text { Zacarías Alonso y } \\
\text { Ulíbarri }\end{array}$ & $\begin{array}{l}\text { Mecanismo para formar rápidamente letras y } \\
\text { cifras }\end{array}$ & Útiles \\
\hline 1909 & $\begin{array}{l}\text { Zacarías Alonso y } \\
\text { Ulíbarri }\end{array}$ & $\begin{array}{l}\text { Procedimiento geométrico-mecánico para } \\
\text { formar rápidamente letras y cifras }\end{array}$ & Útiles \\
\hline 1909 & Ezequiel Rosales & Fórmula para fabricar gises para escuelas & Útiles \\
\hline 1910 & Jacobo Ostos & Tabla para hacer cálculos rápidos & Útiles \\
\hline 1910 & $\begin{array}{l}\text { Zacarías Alonso y } \\
\text { Ulíbarri }\end{array}$ & $\begin{array}{l}\text { Procedimiento mecánico para componer y } \\
\text { descomponer letras, cifras y demás signos }\end{array}$ & Útiles \\
\hline 1910 & Rafael Lorenzo & Aparato para juegos de sport & Mobiliario \\
\hline 1910 & Luis Murillo & $\begin{array}{l}\text { Dibujo de relieve para representar cartas } \\
\text { geográficas (mapas-mundo de relieve para usos } \\
\text { escolares) }\end{array}$ & Didáctico \\
\hline 1910 & Gonzalo Chávez y Cía. & Mesa-banco para escuela "Económica" & Mobiliario \\
\hline 1910 & Mariano del Corral & $\begin{array}{l}\text { Aparato para facilitar el aprendizaje del uso de } \\
\text { los patines }\end{array}$ & Didáctico \\
\hline 1910 & Gonzalo de la Torre & Estuche para escribir & Útiles \\
\hline 1910 & Antonio González & Pinza mixta escolar & Útiles \\
\hline 1910 & $\begin{array}{l}\text { Román Navarro y } \\
\text { Cortés }\end{array}$ & Modelo de un inmueble escolar & Mobiliario \\
\hline 1910 & José Coudurier & $\begin{array}{l}\text { Aparato automático para operaciones aritmé- } \\
\text { ticas }\end{array}$ & Útiles \\
\hline 1910 & José Sanahuja Rivera & Máquina para escribir música y letra & Didáctico \\
\hline 1911 & Gonzalo R. Chávez & Mesa-banco para escuela & Mobiliario \\
\hline
\end{tabular}




\begin{tabular}{|c|l|l|c|}
\hline 1911 & Francisco Gaona Uribe & $\begin{array}{l}\text { Aparato para la enseñanza numérica objetiva } \\
\text { "Redina Mexicana" }\end{array}$ & Didáctico \\
\hline 1911 & Carlos Baur & Procedimiento para hacer gises & Útiles \\
\hline
\end{tabular}

Fuente: elaboración propia con base en los expedientes del fondo de Patentes y Marcas del AGN y los registros de la Gaceta Oficial de la Oficina de Patentes y Marcas.

\section{Referencias}

Basalla, George (1991), La evolución de la tecnología, México, Crítica-Conaculta.

Bazant, Mílada (1995), Historia de la educación durante el Porfiriato, México, El Colegio de México.

Beatty, Edward (1996), "Invención e innovación: ley de patentes y tecnología en el México del siglo XIX", Historia Mexicana, vol. XLV núm. 3, pp. 567-619.

Beatty, Edward (2001), Institutions and Investment. The Political Basis of Industrialization in México Before 1911, Stanford, Stanford University Press.

Beatty, Edward (2015), Technology and search for progress in modern Mexico, Oakland, University of California Press.

Beatty, Edward y Patricio Sáiz (2007), "Propiedad industrial, patentes e inversión en tecnología en España y México (1820-1914)" en Rafael Dobado, Aurora Gómez y Gabriela Márquez (eds.), México y España: ¿historias económicas paralelas?, México, Fondo de Cultura Económica, pp. 425-467.

Bloor, David (1976), Knowledge and social imagery, Londres, Routledge \& Kegan.

Callon, Michel (1986), "Domestication of the Scallops and the Fishermen of St. Brieuc Bay: Some Elements of the Sociology of Translation" en John Law (ed.), Power, Action and Belief: New Sociology of Knowledge, Londres: Routledge \& Kegan, pp. 169-233.

Cutcliffe, Stephen H. (2003), Ideas, máquinas y valores. Los estudios de Ciencia, Tecnología y Sociedad, Barcelona, Anthropos, 2003.

Dussel, Inés (2019), "La cultura material de la escolarización: reflexiones en torno a un giro historiográfico", Educar em Revista, vol. 35, núm. 76, pp. 13-29.

Foucault, Michel (2003), Hay que defender la sociedad. Curso del Collège de France (1975-1976), Madrid, Ediciones Akal.

Gardiner, C. H. (1949), "Las patentes en México de 1867 a 1876", El Trimestre Económico, vol. XVI, núm. 4, pp. 576-599.

González, Moisés (1993), Los extranjeros en México y los mexicanos en el extranjero, 1821-1970, México, El Colegio de México.

Granja, Josefina (2004), Métodos, aparatos y máquinas para la enseñanza en México en el siglo XIX. Imaginarios y saberes populares, México, Pomares-UNAM.

Latour, Bruno (2005), Reensamblar lo social. Una introducción a la teoría del actor en red, Buenos Aires, Manantial.

Layton, Edwin (1977), "Conditions of Technological Development" en Ina Spiegel-Rösing y Derek de Solla Price (eds.), Science, Technology and Society. A Cross-Disciplinary Perspective, Londres, SAGE Publications, pp. 197-222.

Loyo, Engracia y Staples, Anne (2010), "Fin del siglo y de un régimen" en Dorothy Tanck de Estrada (coord.), Historia mínima de la educación en México, México, El Colegio de México, pp. 127-152.

Matute, Álvaro (2000), "Heurística e historia" en Ambrosio Velasco (coord.), El concepto de heurística en las ciencias sociales y las humanidades, México, Siglo XXI-UNAM, pp. 149-163.

Mendoza, Vandari M. (2012), Privilegios e invenciones. Las patentes mexicanas de 1821 a 1876, Morelia, Consejo Estatal de Ciencia, Tecnología e Innovación de Michoacán. 
Mendoza, Vandari M. (2016), "La vida en el aula de los artefactos pedagógicos. Inventos para la enseñanza objetiva en México, 1876-1910” en Paulí Dávila y Luis María Naya (coords). Espacios y patrimonio histórico-educativo, Donostia, Erein, pp. 499-511.

Mendoza, Vandari M. (2017), "En constante movimiento. Dos episodios sobre la circulación de saberes tecnológicos a través de la invención de las máquinas desfibradoras de henequén, siglo XIX", Tzintzun. Revista de estudios históricos, núm. 66, pp. 67-105.

Mendoza, Vandari M. (2018a), "La movilidad del conocimiento tecnológico a través del sistema de patentes. Posibilidades heurísticas en las patentes mexicanas, 1832-1911", Revista Inclusiones, vol. 5, núm. 4, pp. 137-151.

Mendoza, Vandari M. (2018b), Las patentes de invención mexicanas. Instituciones, actores y artefactos. Zamora, El Colegio de Michoacán.

Noble, David (1984), Forces of Production: A Social History of Industrial Automation, Oxford, Oxford University Press.

Oldenziel, Ruth (1999), Making Technology Masculine. Men, Women and Modern Machines in America, 1870-1945, Amsterdam, Amsterdam University Press.

Silver, Harold (1992), "Knowing and not knowing in the history of education", History of Education, vol. 21, núm. 1, pp. 97-108.

Sáiz, Patricio (2002), "Los orígenes de la dependencia tecnológica española. Evidencias en el sistema de patentes", Economía e Industria, núm. 343, pp. 83-95.

Torre, Juan de la (1903), Legislación de patentes y marcas, México, Antigua Imprenta de Murguía.

Wajcman, Judith (2006), El Tecnofeminismo, Madrid: Ediciones Cátedra.

\section{Archivos}

Archivo General de la Nación, Ciudad de México, Fondo: Patentes y Marcas. 